\title{
Medullary Thyroid Cancer: 60 Years of Gradual Understanding
}

\author{
Gerard M. Doherty, MD ${ }^{1,2,3}$ \\ ${ }^{1}$ Crowley Family Distinguished Chair of Surgery, Brigham and Women's Hospital, Boston, MA; ${ }^{2}$ Dana-Farber Cancer \\ Institute, Boston, MA; ${ }^{3}$ Harvard Medical School, Boston, MA
}

Medullary thyroid cancer (MTC) is a relatively less common thyroid cancer subtype that was somewhat recently described and holds an important place in our understanding of thyroid malignancy. Our view of MTC is shaped by the availability of a very sensitive and specific tumor marker (calcitonin), an historic lack of impactful adjuvant therapies beyond surgery (in contrast to follicular cell-derived thyroid cancer), as well as the relative simplicity of the molecular genetics of MTC leading to a special place in our understanding of hereditary tumor syndrome management. The surgical series of MTC resection in this journal issue brings some of these issues into focus as it covers surgery during 30 of the 60 years that we have known about MTC. ${ }^{1}$

MTC was initially described and named as a separate subtype of thyroid cancer in 1959 by Hazard, Hawk, and Crile from the Cleveland Clinic. They consolidated the prior observations of this tumor from themselves and others by detailing 21 patients with "solid" thyroid cancers (no papillary or follicular structure) that included extensive amyloid distribution and frequent lymph node metastases. ${ }^{2}$ The term "medullary" was thought to reflect the solid appearance and intermediate clinical behavior and replaced the prior term: metastasizing amyloid struma. They characterized its clinical course as intermediate between the low-grade course of papillary thyroid cancer and the "highly malignant" course of anaplastic thyroid cancer. Soon after, in 1962, while studying calcium control, Copp described calcitonin, although they believed that calcitonin

(C) Society of Surgical Oncology 2021

First Received: 26 October 2021

Accepted: 28 October 2021;

Published Online: 10 November 2021

G. M. Doherty, MD

e-mail: gmdoherty@BWH.Harvard.edu emanated from the parathyroid glands. ${ }^{3}$ In 1969, Pearse assembled the developing knowledge of MTC, the hormone calcitonin, and the previously described parafollicular thyroid cells that he renamed C-cells, connecting them together to describe the tumor, the tumor marker, and the cell of origin that we now recognize. ${ }^{4}$

Our understanding of the importance of the genetics of MTC followed a similar course after the 1959 Hazard, Hawk, and Crile description. In 1961, Sipple described a familial syndrome that included MTC, pheochromocytoma, and hyperparathyroidism, and Steiner introduced the concepts of multiple endocrine neoplasia-2 (MEN-2) syndromes in 1968. ${ }^{5}, 6$ Abnormalities of the RET protooncogene as the cause of MEN-2 syndromes were discovered in 1993, leading to the first prophylactic operation for any disease based upon germline detection of a familial syndrome. ${ }^{7,8}$

Throughout this refinement of our disease understanding, surgical resection was recognized as the mainstay of therapy for MTC, necessarily adopting the Halstedian view of cancer treatment that a sufficiently complete operation in a patient with local-regional disease was the sole opportunity for cure. Taking great care to select patients with apparently limited disease, including such approaches as laparoscopy for identification of hepatic micrometastases, patients underwent thyroidectomy and compartment-based nodal microdissection in an attempt to remove all disease and to render the calcitonin undetectable, even with pentagastrin stimulation. Over time, and with the increasing sensitivity of calcitonin testing, it became clear that true biochemical cures were rare, but that long-term disease control was possible. ${ }^{9}$

The need for effective systemic treatments has been very clear both for patients whose distant disease was not amenable to the local-regional approaches, and in an adjuvant setting after apparent complete resection. That need led to some wishful thinking. Until relatively recently, 
there remained some dispute about the value of radioactive iodine (RAI) for the treatment of MTC. Although it was recognized that the MTC cells lacked the ability to concentrate RAI themselves, there was hope that the RAI sequestered in adjacent thyroid follicular cells would crossirradiate the MTC cells. After many contradictory clinical and animal experiment publications, it is now settled that RAI has no place in the treatment of MTC; however, the long persistence of that hope is emblematic of the challenges in determining best management for a less common, indolent disease without effective adjuvant options. ${ }^{10}$

Happily, more recently there has finally been progress on effective systemic therapy, as molecularly targeted systemic therapies using tyrosine kinase inhibitors (TKI) have shown impact on MTC in patients. This has spawned tests of the potential effect and uses of these treatments for patients in various categories of disease. The groups believed likely to benefit include mostly those with progressive metastatic disease but also patients with locally advanced disease, and in an adjuvant setting for high-risk patients after resection.

The currently reported series from the experienced and expert clinical group at Royal North Shore Hospital and the University of Sydney catalogues some of that evolution in surgery and particularly crosses the time period before and after the introduction of TKI therapy. ${ }^{1}$ The strengths of their report are the recognized excellence of the group, their thorough follow-up for long periods, and the evolution of their approaches reflected here. My most important conclusion from their work is that there was disappointingly little change over time, with the introduction of TKI therapy having less overall impact than I had hoped. I also was struck by their observation of the significant neck morbidity of the operations that they undertook for these patients, which mirror my own impressions of this group of complex patients. Clearly, despite all of our progress, we have further room to improve the outcomes of our overall treatment strategy.

Looking forward, there is hope that more selective, less toxic TKI therapy will enable better use both for known distant metastases, and in an adjuvant setting. Our strategies will improve; a particularly enticing use for TKI is in patients with locally advanced disease who are planned for surgical resection, which often includes significant morbidity from recurrent nerve resection. As these authors note, and we all hope, effective systemic therapy might allow us to shrink the local tumor prior to operation, and potentially reduce the morbidity of resection. We can all anticipate additional cogent guidance from the Royal North Shore group as they build their experience with that neoadjuvant use, and continue to add to the ongoing story of MTC that has played out over the past six decades.

\section{REFERENCES}

1. Kesby N, Gild M, Aniss A, Sywak M, Clifton-Bligh R, Sidhu S, Glover A. Outcomes of advanced medullary thyroid carcinoma in the era of targeted therapy. Ann Surg Oncol. 2021. https://doi.org/ 10.1245/s10434-021-10980-5.

2. Hazard JB, Hawk WA, Crile G. Medullary (solid) carcinoma of the thyroid-a clinicopathologic entity. J Clin Endocrin Metab. 1959;19(1):152-61. https://doi.org/10.1210/jcem-19-1-152.

3. Copp DH, Cheney B. Calcitonin-a hormone from the parathyroid which lowers the calcium-level of the blood. Nature. 1962;193:381-2. https://doi.org/10.1038/193381a0.

4. Bussolati G, Foster GV, Clark MB, Pearse AG. Immunofluorescent localisation of calcitonin in medullary C-cell thyroid carcinoma, using antibody to the pure porcine hormone. Virchows Arch B Cell Pathol. 1969;2(3):234-8. https://doi.org/10.1007/ BF02889587.

5. Sipple JH. The association of pheochromocytoma with carcinoma of the thyroid gland. Am J Med. 1961;31:163-6.

6. Steiner AL, Goodman AD, Powers SR. Study of a kindred with pheochromocytoma, medullary thyroid carcinoma, hyperparathyroidism and Cushing's disease: multiple endocrine neoplasia, type 2. Medicine (Baltimore). 1968;47(5):371-409. h ttps://doi.org/10.1097/00005792-196809000-00001.

7. Donis-Keller H, Dou S, Chi D, Carlson KM, Toshima K, Lairmore TC, Howe JR, Moley JF, Goodfellow P, Wells SA Jr. Mutations in the RET proto-oncogene are associated with MEN 2A and FMTC. Hum Mol Genet. 1993;2(7):851-6. https://doi.org/ 10.1093/hmg/2.7.851 (PMID: 8103403).

8. Skinner MA, Moley JA, Dilley WG, Owzar K, Debenedetti MK, Wells SA Jr. Prophylactic thyroidectomy in multiple endocrine neoplasia type 2A. $N$ Engl J Med. 2005;353(11):1105-13. http s://doi.org/10.1056/NEJMoa043999.

9. Fialkowski E, DeBenedetti M, Moley J. Long-term outcome of reoperations for medullary thyroid carcinoma. World J Surg. 2008;32(5):754-65. https://doi.org/10.1007/s00268-007-9317-7.

10. Meijer JAA, Bakker LEH, Valk GD, de Herder WW, de Wilt JHW, Netea-Maier RT, Schaper N, Fliers E, Lips P, Plukker JT, Links TP, Smit JA. Radioactive iodine in the treatment of medullary thyroid carcinoma: a controlled multicenter study. Eur J Endocrinol. 2013;168(5):779-86.

Publisher's Note Springer Nature remains neutral with regard to jurisdictional claims in published maps and institutional affiliations. 